\title{
Exigências de Manganês para Frangos de Corte nas Fases de Crescimento e Terminação ${ }^{1}$
}

\author{
Edwiney Sebastião Cupertino2 ${ }^{2}$, Paulo Cezar Gomes ${ }^{3}$, Luiz Fernando Teixeira Albino ${ }^{4}$, Horacio \\ Santiago Rostagno ${ }^{5}$, Paulo Roberto Cecon ${ }^{6}$, Marlene Schimidt ${ }^{7}$
}

\begin{abstract}
RESUMO - Com os objetivos de determinar a exigência de manganês nas fases de crescimento (22 a 42 dias) e terminação (43 a 54 dias), foram realizados dois experimentos utilizando-se 480 frangos de corte, distribuídos em um esquema fatorial 6 x 2 (seis níveis de manganês e dois sexos - macho e fêmea), em delineamento inteiramente casualizado, com quatro repetições. Utilizaram-se seis e quatro aves por unidade experimental, no primeiro e segundo experimentos, respectivamente. Em ambos os ensaios, os tratamentos consistiram de uma dieta basal deficiente em manganês (6,5 ppm) ou suplementada com 0, 30, 60, 90, 120 e 150 ppm de manganês, proveniente do sulfato de manganês comercial. As variáveis avaliadas foram ganho de peso, consumo de ração, conversão alimentar, comprimento de tíbia, resistência do osso à quebra e concentração de manganês no fígado e nos ossos. Os níveis de manganês, na fase de crescimento, influenciaram as concentrações de manganês no fígado e no osso e, na fase de terminação, alteraram a concentração de manganês no fígado. As exigências de manganês foram estimadas pelos modelos de regressão polinomial e LRP (Linear Response Plateau). A exigência de manganês para frangos de corte, machos e fêmeas, na fase de crescimento é de 90 ppm. Na fase de terminação, os níveis de 30 a 40 ppm de manganês, normalmente presentes em dietas práticas à base de milho e farelo de soja, são suficientes para o desenvolvimento das aves.
\end{abstract}

Palavras-chave: desempenho, frango, manganês, nutrição, osso

\section{Manganese Requeriments for Broilers in the Growing and Finishing Phases}

ABSTRACT - Four hundred and eighty broilers were assigned to a completely randomized design with a 6x2 arrangement (six levels of manganese and 2 sexes - male and female) and four replicates to determine the manganese requirements in the growing (22 to 42 days) and finishing (43 to 54 days) phases. Six and four birds per experimental unit, respectively, were used in the first and second trials. In both trials, the treatments consisted of a basal diet deficient in manganese (6.5 ppm) or supplemented with manganese (0, 30, 60, 90, 120, and 150 ppm) from the commercial sulfate. The following variables were analyzed: weight gain, feed intake, feed conversion, tibia length, resistance of bone to breaking, and manganese concentration in the liver and bone. The levels of manganese influenced the manganese concentration in the liver and bone in the growing phase and the manganese concentration in the liver in the finishing phase. The manganese requirements were estimated by the polynomial regression models and LRP (Linear Response Plaeau). The manganese requirement was estimated in 90 ppm for male and female broilers in the growing phase. In the finishing phase, the levels from 30 to 40 ppm of manganese is recommended to obtain good results of performance for birds fed corn and soybean meal-based diets.

Key Words: performance, mineral, manganese, chicken, bone

\section{Introdução}

A avicultura de corte é uma das atividades que mais se desenvolveram nos últimos anos. Entretanto, com os avanços no melhoramento genético, tem sido constante a necessidade de pesquisas visando à adequação das exigências nutricionais das aves nas diferentes fases de criação. Esses estudos permitiram a redução nos custos de produção, como conseqüência da maior eficiência obtida.

As exigências de minerais, assim como os requerimentos nutricionais, variam conforme a fase de criação em que as aves se encontram e normalmente são reduzidas com o avanço da idade dos frangos de corte. Esta tendência justifica estudos para determinar o que realmente é necessário ao melhor desenvolvimento animal, evitando a contaminação excessiva do ambiente e os custos adicionais com suplementação mineral inadequada.

O manganês participa em funções importantes no organismo animal, sobretudo na matriz óssea, e sua deficiência pode provocar anormalidades nas pernas e nos dedos, além de incidência de perose.

\footnotetext{
1 Parte da tese apresentada pelo primeiro autor à UFV para obtenção do título de Magister Scientiae.

2 Estudante de Pós-graduação do Departamento de Zootecnia - UFV, Viçosa MG, Brasil. CEP: 36571-000 (edwiney@coopeavi.com.br)

3 Professor do Departamento de Zootecnia - UFV, Viçosa MG, Brasil. CEP: 36571-000.

4 Professor do Departamento de Zootecnia - UFV, Viçosa MG, Brasil. CEP: 36571-000.

5 Professor do Departamento de Zootecnia - UFV, Viçosa MG, Brasil. CEP: 36571-000.

6 Professor do Departamento de Informática - UFV, Viçosa MG, Brasil. CEP: 36571-000.

7 Estudante de Pós-graduação do Departamento de Zootecnia - UFV, Viçosa MG, Brasil. CEP: 36571-000.
} 
A exigência nutricional de manganês suplementar para frangos de corte, segundo o NRC (1994), é de 60 ppm e, de acordo com Rostagno et al. (2000), de 70 ppm.

O objetivo neste trabalho foi estabelecer a exigência nutricional de manganês para frangos de corte, machos e fêmeas, nas fases de crescimento (22 a 42 dias) e terminação (43 a 54 dias).

\section{Material e Métodos}

Foram desenvolvidos dois experimentos no Departamento de Zootecnia da Universidade Federal de Viçosa. No primeiro experimento, foram utilizadas aves de 22 a 42 dias de idade e, no segundo, aves (distintas do primeiro ensaio) de 43 a 54 dias de idade.

Foram utilizados 480 frangos de corte da linhagem Avian Farms, metade de cada sexo, distribuídos em um esquema fatorial $6 \times 2$ (seis níveis de manganês e dois sexos - macho e fêmea) em delineamento inteiramente casualizado, com quatro repetições e seis e quatro aves por unidade experimental, respectivamente, no primeiro e segundo experimentos.

Determinaram-se os valores de proteína bruta, cálcio, fósforo total e manganês dos ingredientes das rações experimentais (Silva, 1998). Foram analisadas amostras diárias da água fornecida aos animais, encontrando-se apenas traços de manganês 0,00011 ppm).

A dieta basal foi elaborada para atender as exigências nutricionais das aves, segundo recomendações de Rostagno et al. (2000), com exceção do manganês, que permaneceu deficiente com nível de 6,5 ppm (Tabela 1).

Em ambos os experimentos, os tratamentos consistiram da suplementação com 0, 30, 60, 90, 120 e 150 ppm de manganês em substituição à areia lavada, utilizada como inerte nas dietas experimentais, perfazendo um total de 6,5; 36,5; 66,5; 96,5; 126,5 e 156,5 ppm. As aves receberam ração e água à vontade e foram mantidas sob programa de luz contínua, com 24 horas de luz (natural + artificial). As pesagens foram realizadas no início e final de cada ensaio, para averiguação do ganho de peso, do consumo de ração e da conversão alimentar. Ao término dos experimentos, foram abatidas 144 aves do primeiro experimento (três por boxe) e 96 aves do segundo experimento (duas por boxe), para extração do fígado e da tíbia, visando à análise da concentração de manganês e à aferição do comprimento e da resistência à quebra da tíbia.

As concentrações de manganês foram estimadas no fígado e na tíbia esquerda (com as cartilagens
Tabela 1 - Composição percentual e valor nutricional das dietas basais

Table 1 - Ingredient composition and nutritional value of basal diets

\begin{tabular}{|c|c|c|}
\hline $\begin{array}{l}\text { Ingrediente } \\
\text { Ingredient }\end{array}$ & $\begin{array}{l}\text { Dieta basal I } \\
\text { Basal diet I }\end{array}$ & $\begin{array}{c}\text { Dieta basal I } \\
\text { Basal diet II }\end{array}$ \\
\hline & $-(9$ & \\
\hline Milho moído (Milled corn) & 63,758 & 64,098 \\
\hline Glúten de milho (Corn gluten) & 2,26 & 0,40 \\
\hline Farinha de carne (Meat meal) & 5,34 & 4,60 \\
\hline Farelo de soja (Soybean meal) & 25,41 & 25,80 \\
\hline Calcário (Limestone) & 0,20 & 0,24 \\
\hline Fosfato bicálcico & 0,08 & 0,08 \\
\hline Dicalcium phosphate & & \\
\hline Óleo vegetal (Vegetable oil) & 1,93 & 3,9 \\
\hline Sal (Salt) & 0,30 & 0,31 \\
\hline Mistura vitamínica ${ }^{1}$ & 0,10 & 0,10 \\
\hline Vitamin premix & & \\
\hline Mistura mineral $^{2}$ & 0,10 & 0,10 \\
\hline Mineral premix & & \\
\hline Antioxidante (Antioxidant) ${ }^{3}$ & 0,01 & 0,01 \\
\hline Anticoccidiano $^{4}$ & 0,05 & 0,05 \\
\hline Coccidiostatic & & \\
\hline Promotor de crescimento 5 & 0,002 & 0,002 \\
\hline Growth promoter & & \\
\hline DL-metionina, 99\% & 0,15 & 0,12 \\
\hline DL-methionine & & \\
\hline Lisina $\mathrm{HCl}, 78 \%$ (Lysine) & 0,21 & 0,09 \\
\hline Areia lavada (Washed sand) & 0,10 & 0,10 \\
\hline
\end{tabular}

Composição calculada

Calculated composition

\begin{tabular}{lcc}
\hline Proteína bruta (\%) & 19,80 & 18,50 \\
Crude protein & & \\
EM (ME) (kcal/kg) & 3100,00 & 3200,00 \\
$\begin{array}{l}\text { Fibra bruta (\%) } \\
\text { Crude fiber }\end{array}$ & 2,837 & 2,839 \\
$\begin{array}{l}\text { Ácido linoléico (\%) } \\
\text { Linoleico acid }\end{array}$ & 2,501 & 3,521 \\
Ca (\%) & 0,874 & 0,800 \\
P disponível (\%) & 0,406 & 0,365 \\
AvailableP & & \\
Na (\%) & 0,192 & 0,192 \\
Mn (mg/kg) & 6,5 & 6,5 \\
Lisina total (\%) (Total lysine) & 1,156 & 1,040 \\
Metionina total (\%) & 0,481 & 0,419 \\
Total methionine & & \\
Met.+Cistina (\%) & 0,825 & 0,742 \\
$\begin{array}{l}\text { Methionine + cystine } \\
\text { Treonina total (\%) }\end{array}$ & 0,771 & 0,732 \\
Total threonine & & \\
Triptofano total (\%) & 0,220 & 0,216 \\
Total tryptophan & & \\
\hline
\end{tabular}

${ }^{1}$ Conteúdo/kg (content/kg): Vit. A - 12.000 .000 U.I; Vit. D3 3.600 .000 U.I; Vit.B1 - 2.500 mg; Vit. B2 - 8.000 mg; Vit. B6 $5.000 \mathrm{mg}$; Ácido pantotênico (Panthotenic acid) - 12.000 mg; Biotina (Biotin) - 200 mg; Vit. K3 - 3.000 mg; Ác. fólico (Folic acid) $1.500 \mathrm{mg}$; Ác. nicotínico (Nicotinic acid) - 40.000 mg; Vit. B12 20.000 mcg; Se - 150 mg; Veículo (vehicle), q.s.p - 1000 g.

2 Conteúdo/kg (content/kg): $\mathrm{Fe}$ - 50,0 g; Cu - 8,5g; Zn - 60,0 g; Co $0,2 \mathrm{~g} ; \mathrm{I}-1,0 \mathrm{~g}$; Se - 0,10 g; Veículo (vehicle), q.s.p - $1000 \mathrm{~g}$.

3 BHT.

${ }^{4}$ Coxistac - Salinomicina sódica (Salinomicine sodic), 12\%.

${ }^{5}$ Stafac - Virginiamicina (Virginiamicine), 50\%. 
adjacentes e livres de tecido muscular), de acordo com a metodologia descrita por Silva (1998), em espectrofotômetro de absorção atômica, modelo 908, marca GBC, e as análises de resistência dos ossos à quebra foram realizadas com a tíbia direita, livre de tecidos musculares, utilizando os ossos in natura, utilizando-se um aparelho que calcula a força de resistência de materiais (INSTRON-modelo 4204).

As análises estatísticas dos parâmetros avaliados neste experimento foram realizadas pelo programa SAEG (Sistema para Análises Estatísticas e Genéticas), versão 8.0, desenvolvido pela Universidade Federal de Viçosa (1999), utilizando-se o modelo quadrático e/ou "Linear Response Plateau" (LRP), conforme ajustamento dos dados obtidos para cada variável.

\section{Resultados e Discussão}

Durante a fase de 22 a 42 dias de idade, não foi observada incidência de perose nas aves, o que está de acordo com os resultados obtidos por Fialho et al. (1993), que também não constataram incidência de perose em aves alimentadas com dieta à base de milho e farelo de soja sem manganês suplementar durante o período de 1 a 49 dias de idade. Segundo esses autores, os níveis de manganês propostos pelo NRC (1994) podem estar superestimados para aves de rápido crescimento. Contudo, Scott (1981) comenta que, para prevenção da perose, não somente os níveis de manganês, como os de outros nutrientes (ácido fólico e vitamina B6), devem estar adequados. Portanto, é possível que esta anormalidade óssea não tenha sido provocada pelas dietas experimentais contendo quantidades suplementares consideráveis destas vitaminas.

As incidências de anormalidades de pernas e dedos foram raras e aleatórias e, portanto, não podem ser atribuídas a efeitos de tratamento.

Na Tabela 2 são apresentados os dados de desempenho das aves. Não se verificou efeito da interação sexo $\mathrm{x}$ níveis de manganês $(\mathrm{P}>0,05)$, comprovando estes fatores agem de forma independente sobre o desempenho das aves. Também não houve efeito dos níveis de manganês $(\mathrm{P}>0,05)$ sobre o ganho de peso, o consumo de ração e a conversão alimentar. Fialho et al. (1993) e Nobre (1993) também não observaram efeito dos níveis de manganês sobre o desempenho de frangos de corte. Henry et al. (1986) comenta que a deficiência de manganês pode não afetar o desempe- nho de animais alimentados com dietas práticas à base de milho de farelo de soja, pois essas dietas permitem às aves expressarem seu máximo potencial genético. De fato, relatos de influência do manganês sobre o desempenho dos animais ocorreram somente quando foram utilizados níveis muito altos, promovendo sintomas de toxidez (Southern \& Baker, 1983) ou quando houve deficiência severa provocada com dietas purificadas (Keaky \& Sullivan, 1966).

Verificou-se efeito do sexo $(\mathrm{P}<0,01)$ sobre $\mathrm{o}$ desempenho dos frangos de corte, uma vez que os machos consumiram $8,5 \%$ a mais de ração, ganharam $16,2 \%$ a mais de peso e apresentaram conversão alimentar 6,7\% melhor que as fêmeas.

Os resultados referentes ao comprimento de tíbia, às concentrações de manganês no fígado e no osso e à resistência do osso à quebra nos frangos de corte na fase de 22 a 42 dias de idade encontram-se na Tabela 3.

Não houve interação de sexo e níveis de manganês $(\mathrm{P}>0,05)$, comprovando que estes fatores atuam de forma independente sobre estas variáveis.

Constataram-se efeitos significativos $(\mathrm{P}<0,01)$ de sexo; os frangos machos tiveram maior resistência do osso à quebra, menor concentração de manganês no fígado e no osso e maior comprimento de tíbia que as fêmeas.

Os níveis crescentes de manganês na dieta influenciaram significativamente $(\mathrm{P}<0,01)$ a concentração de manganês nos ossos e no fígado, confirmando os relatos de Andriguetto (1981) e Leeson \& Summers (2001).

Os níveis de manganês influenciaram de forma linear $(\mathrm{P}<0,01)$ a deposição de manganês no fígado (Tabela 3), indicando que esse órgão acumula o manganês fornecido em excesso nas dietas, não podendo ser utilizado para determinação das exigências desse mineral para aves.

Como não houve interação $(\mathrm{P}>0,05)$ entre sexo e níveis de manganês as equações foram ajustadas para ambos os sexos.

A exigência de manganês estimada pelo modelo quadrático foi de 136 ppm e, pelo modelo Linear Response Plateou (LRP), de 90 ppm (Tabela 4). Portanto, a estimativa de exigência obtida pelo modelo quadrático foi maior que a do LRP. Morris (1983) argumentou que o modelo quadrático pode proporcionar bom ajuste de dados, causando uma falsa segurança, uma vez que a curvatura é muito 
Tabela 2 - Desempenho de frangos de corte de 22 a 42 dias de idade, machos (M) e fêmeas (F), submetidos a diferentes níveis de manganês $(\mathrm{Mn})$ na dieta

Table 2 - Performance of male (M) and female (F) broilers fed diets with different levels of manganese (Mn) levels from 22 to 42 days old

\begin{tabular}{|c|c|c|c|c|}
\hline $\begin{array}{l}\text { Nível de } \mathrm{Mn}(\mathrm{ppm}) \\
\text { Level of } M n\end{array}$ & $\begin{array}{l}\text { Sexo } \\
\text { Sex }\end{array}$ & $\begin{array}{l}\text { Ganho de peso (g/ave) } \\
\text { Body weight gain (g/bird) }\end{array}$ & $\begin{array}{l}\text { Consumo de ração (g/ave) } \\
\text { Feed intake (g/bird) }\end{array}$ & $\begin{array}{c}\text { Conversão alimentar (g:g) } \\
\text { Feed:gain ratio }\end{array}$ \\
\hline 6,5 & M & 1684,6 & 3039,0 & 1,81 \\
\hline 36,5 & M & 1620,2 & 2929,0 & 1,81 \\
\hline 66,5 & M & 1616,3 & 2918,0 & 1,81 \\
\hline 96,5 & M & 1605,9 & 2896,0 & 1,80 \\
\hline 126,5 & M & 1728,1 & 3051,0 & 1,77 \\
\hline 156,5 & M & 1687,3 & 3059,0 & 1,81 \\
\hline Média & & $1657,1 \mathrm{a}$ & 2981,9a & $1,80 \mathrm{~b}$ \\
\hline \multicolumn{5}{|l|}{ Mean } \\
\hline 6,5 & $\mathrm{~F}$ & 1463,7 & 2788,0 & 1,91 \\
\hline 36,5 & $\mathrm{~F}$ & 1418,2 & 2741,0 & 1,93 \\
\hline 66,5 & $\mathrm{~F}$ & 1417,0 & 2763,0 & 1,95 \\
\hline 96,5 & F & 1417,7 & 2726,0 & 1,93 \\
\hline 126,5 & $\mathrm{~F}$ & 1408,7 & 2718,0 & 1,93 \\
\hline 156,5 & $\mathrm{~F}$ & 1430,7 & 2743,0 & 1,92 \\
\hline Média & & $1426,0 \mathrm{~b}$ & $2746,5 b$ & 1,93a \\
\hline \multicolumn{5}{|l|}{ Mean } \\
\hline Níveis de Mn & & $\mathrm{ns}$ & $\mathrm{ns}$ & ns \\
\hline \multicolumn{5}{|l|}{ Levels of Mn } \\
\hline Sexo (Sex) & & ** & ** & ** \\
\hline Sexo x Níveis & & $\mathrm{ns}$ & ns & $\mathrm{ns}$ \\
\hline \multicolumn{5}{|l|}{ Sex $\times$ Levels } \\
\hline CV (\%) & & 4,71 & 3,38 & 2,34 \\
\hline
\end{tabular}

Médias seguidas pela mesma letra na coluna não diferem a $5 \%$ pelo teste $\mathrm{F}$.

Averages followed by the same letter in the column do not differ at $5 \%$ by $F$ test.

CV-Coeficiente de variação (Coefficient of variation).

** $(P<0,01)$; ns $(P>0,05)$, pelo teste $F$ (by $F$ test).

sensível a variações nos intervalos dos tratamentos e que o modelo é fisiologicamente incorreto, pois pressupõe respostas simétricas para deficiência e para excesso. O autor comenta ainda que o ajuste de dados pelo modelo LRP pode proporcionar bom ajuste estatístico, mas freqüentemente subestima o nível ótimo.

Em razão do melhor ajuste estatístico e da menor soma de quadrado dos desvios, proporcionada pelo modelo LRP, concluiu-se que a exigência de manganês para frangos de corte, machos e fêmeas, de 22 a 42 dias de idade é de 90 ppm. Esse resultado está próximo ao recomendado, como suplemento na ração, por Rostagno et al. (2000), de 70 ppm, e pelo NRC (1994) que é de 60 ppm, considerando-se que as dietas práticas fornecidas a frangos de corte já contêm normalmente de 30 a 40 ppm de manganês.

Constam na Tabela 5 os resultados de desempenho dos frangos de corte de 43 a 54 dias de idade alimentados com dietas contendo diferentes níveis de manganês.
Como observado na fase de crescimento, também não se constatou incidência de perose na aves, o que está de acordo com os dados reportados por Fialho et al. (1993). Incidências de anormalidades de pernas e dedos também foram raras e não puderam ser atribuídas a efeitos de tratamento.

Não houve efeito da interação sexo x níveis de manganês na dieta $(\mathrm{P}>0,05)$ sobre as variáveis de desempenho, comprovando que esses fatores agem de forma independente.

Os níveis de manganês na dieta $(\mathrm{P}>0,05)$ não influenciaram o ganho de peso, o consumo de ração e a conversão alimentar, confirmando que os níveis de manganês estudados não interferem no desempenho das aves, concordando com os resultados obtidos por Henry et al. (1986), Fialho et al. (1993) e Nobre (1993). Porém, ocorreu efeito de sexo $(\mathrm{P}<0,01)$ onde os machos ganharam $7,0 \%$ a mais de peso, consumiram $13,6 \%$ a mais de ração e apresentaram conversão alimentar 7,0\% melhor que as fêmeas. 
Tabela 3 - Efeitos de diferentes níveis de manganês $(\mathrm{Mn})$ na ração sobre a resistência do osso à quebra (ROQ), o comprimento da tíbia (CT) e a concentração de $\mathrm{Mn}$ no osso (MnO) e no fígado (MnF) de frangos de corte machos (M) e fêmeas (F) de 22 a 42 dias de idade

Table 3 - Effects of different dietary levels of manganese (Mn) on bone fracture resistance (ROQ), tibia length (CT), and Mn concentration in the bone $(\mathrm{MnO})$ and in the liver $(\mathrm{MnF})$ for male $(\mathrm{M})$ and female $(F)$ broilers from 22 to 42 days old

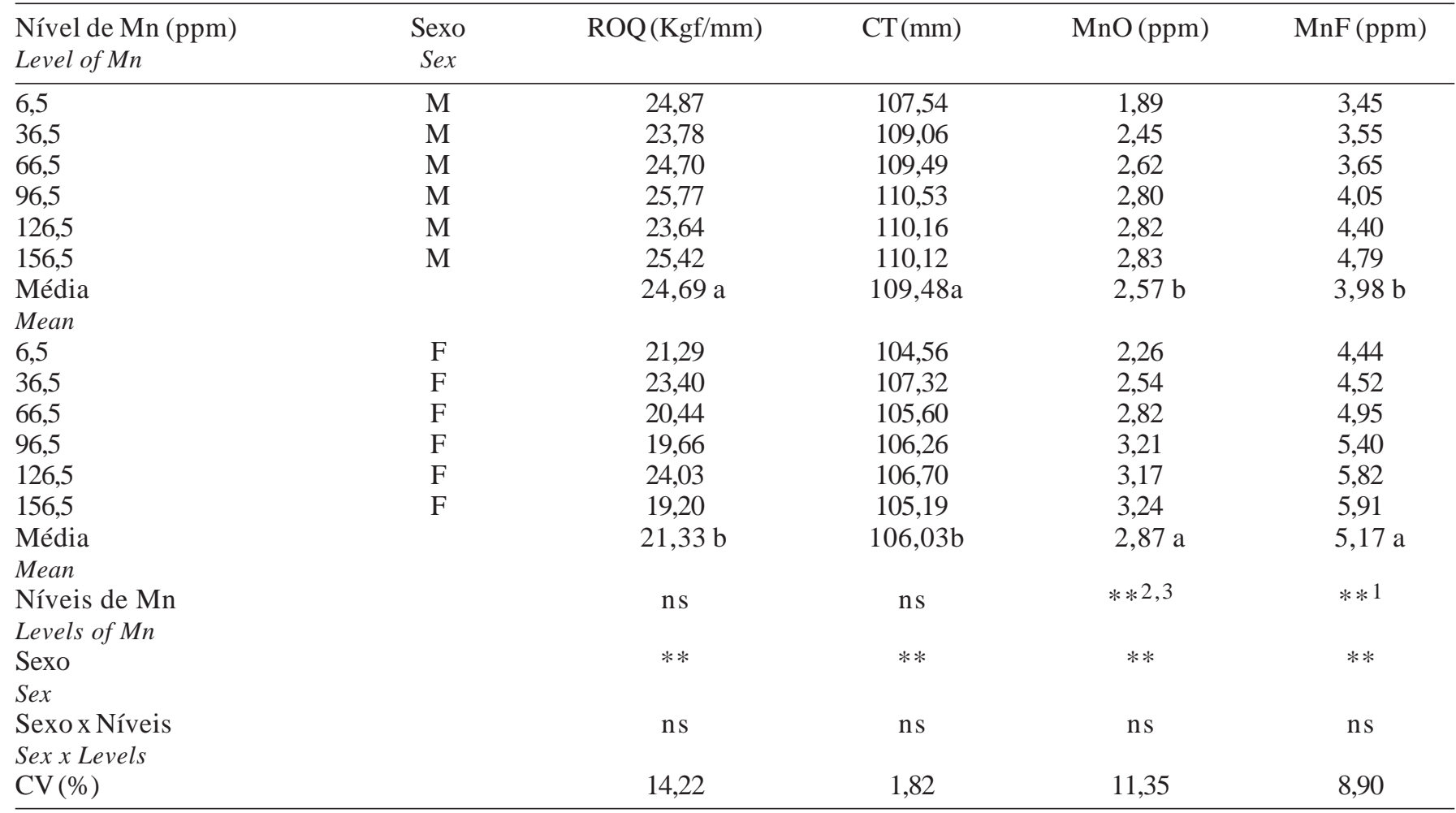

Médias seguidas pela mesma letra na coluna não diferem a $5 \%$ pelo teste $\mathrm{F}$.

Averages followed by the same letter in the column do not differ at $5 \%$ by $F$ test.

$\mathrm{CV}$ - Coeficiente de variação (Coefficient of variation).

** $(P<0,01) ;$ ns $(P>0,05)$, pelo teste $F$ (by $F$ test).

1 Efeito linear (Linear effect).

2 Linear Response Plateau (LRP) (Linear and Linear Response Plateau effect).

${ }^{3}$ Efeito quadrático (Quadratic effect).

Tabela 4 - Sumário das análises de determinação das exigências de manganês (Mn), estimadas pelos modelos quadrático e Linear Response Plateau (LRP), para frangos de corte de 22 a 42 dias de idade

Table 4 - Summary of the determination analyses of manganese $(\mathrm{Mn})$ requeriments estimated by the quadratic and linear response plateau (LRP) models for broilers from 22 to 42 days old

\begin{tabular}{|c|c|c|c|c|c|}
\hline \multicolumn{6}{|c|}{$\begin{array}{c}\text { Modelo quadrático } \\
\text { Quadratic model }\end{array}$} \\
\hline $\begin{array}{l}\text { Variável } \\
\text { Variable }\end{array}$ & $\begin{array}{c}\text { Equações ajustada } \\
\text { Fitted equations }\end{array}$ & & $\begin{array}{l}\text { Exigência } \\
\text { Requirement }\end{array}$ & $\mathrm{r}^{2}$ & SQD \\
\hline $\mathrm{MnO}(\mathrm{ppm})$ & $\hat{\mathrm{Y}}=1,97817+0,0156358 \mathrm{~N}-0,0$ & $46 N^{2}$ & 136,32 & 0,98 & 0,0077 \\
\hline \multicolumn{6}{|c|}{$\begin{array}{l}\text { Linear Response Plateou } \\
\text { Linear Response Plateau }\end{array}$} \\
\hline $\begin{array}{l}\text { Variável } \\
\text { Variable }\end{array}$ & $\begin{array}{l}\text { Equação da reta } \\
\text { Line equation }\end{array}$ & $\begin{array}{c}\text { Platô } \\
\text { Plateau }\end{array}$ & $\begin{array}{l}\text { Exigência } \\
\text { Requirement }\end{array}$ & $r^{2}$ & $S Q D$ \\
\hline $\mathrm{MnO}(\mathrm{ppm})$ & $\hat{\mathrm{Y}}=2,0342+0,0108 \mathrm{~N}$ & $\mathrm{Y}=3,01$ & 90,59 & 0,99 & 0,0070 \\
\hline
\end{tabular}

** $(\mathrm{P}<0,01)$ pelo teste $\mathrm{F}$ (by $\mathrm{F}$ test).

SQD - Soma de quadrado dos desvios (Square sum of deviations).

$\mathrm{MnO}$ - Manganês no osso (Manganese in the bone). 
Tabela 5 - Desempenho de frangos de corte de 43 a 54 dias de idade, machos (M) e fêmeas (F), submetidos a diferentes níveis de manganês (Mn) na dieta

Table 5 - Performance of male (M) and female (F) broilers fed diets with different levels of manganese (Mn) levels from 43 to 54 days old

\begin{tabular}{|c|c|c|c|c|}
\hline $\begin{array}{l}\text { Nível de Mn (ppm) } \\
\text { Level of } M n\end{array}$ & $\begin{array}{l}\text { Sexo } \\
\text { Sex }\end{array}$ & $\begin{array}{l}\text { Ganho de peso (g/ave) } \\
\text { Body weight gain (g/bird) }\end{array}$ & $\begin{array}{l}\text { Consumo de ração (g/ave) } \\
\text { Feed intake (g/bird) }\end{array}$ & $\begin{array}{c}\text { Conversão alimentar (g:g) } \\
\text { Feed:gain ratio }\end{array}$ \\
\hline 6,5 & M & 1003,4 & 2432,2 & 2,44 \\
\hline 36,5 & M & 978,7 & 2351,8 & 2,40 \\
\hline 66,5 & M & 958,5 & 2259,7 & 2,36 \\
\hline 96,5 & M & 975,7 & 2263,8 & 2,32 \\
\hline 126,5 & M & 877,6 & 2147,0 & 2,45 \\
\hline 156,5 & M & 947,5 & 2185,6 & 2,31 \\
\hline Média & & $956,9 a$ & 2273,3a & $2,38 b$ \\
\hline \multicolumn{5}{|l|}{ Mean } \\
\hline 6,5 & $\mathrm{~F}$ & 717,8 & 1895,3 & 2,65 \\
\hline 36,5 & $\mathrm{~F}$ & 782,8 & 1978,2 & 2,53 \\
\hline 66,5 & F & 785,4 & 1985,0 & 2,54 \\
\hline 96,5 & F & 899,1 & 2075,3 & 2,39 \\
\hline 126,5 & $\mathrm{~F}$ & 787,2 & 2057,8 & 2,61 \\
\hline 156,5 & F & 772,5 & 2009,0 & 2,60 \\
\hline Média & & $790,8 b$ & $2000,1 b$ & 2,56a \\
\hline \multicolumn{5}{|l|}{ Mean } \\
\hline Níveis de Mn & & ns & ns & ns \\
\hline \multicolumn{5}{|l|}{ Levels of Mn } \\
\hline Sexo & & $* *$ & $* *$ & $* *$ \\
\hline \multicolumn{5}{|l|}{ Sex } \\
\hline Sexo x Níveis & & ns & ns & ns \\
\hline \multicolumn{5}{|l|}{ Sex $\times$ Levels } \\
\hline CV (\%) & & 10,53 & 6,73 & 7,91 \\
\hline
\end{tabular}

Médias seguidas pela mesma letra na coluna não diferem a $5 \%$ pelo teste $\mathrm{F}$.

Averages followed by the same letter in the column do not differ at $5 \%$ by $F$ test.

CV - Coeficiente de variação (Coefficient of variation).

** $(P<0,01)$; ns $(P>0,05)$, pelo teste $F($ by $F$ test).

Não foi observado efeito da interação sexo $\mathrm{x}$ níveis de manganês na dieta $(\mathrm{P}>0,05)$ sobre a resistência do osso à quebra, o comprimento da tíbia, a concentração de Mn no osso e no fígado de frangos dos corte na fase de 43 a 54 dias de idade (Tabela 6), sugerindo que estes fatores atuam de forma independente sobre estas variáveis.

Os frangos machos apresentaram menor deposição de manganês no osso e no fígado e maior comprimento de tíbia que as fêmeas, comprovando efeito $(\mathrm{P}<0,01)$ do sexo sobre essas variáveis.

Os níveis de manganês não influenciaram $(\mathrm{P}>0,05)$ o comprimento da tíbia, a concentração de manganês no osso e a resistência do osso à quebra. Entretanto, constatou-se efeito $(\mathrm{P}<0,01)$ do nível de manganês na dieta sobre a concentração de manganês no fígado.

Embora tenha-se observado efeito linear $(\mathrm{P}<0,01)$ na deposição do manganês dietético no fígado das aves, essa variável não deve ser considerada na determinação da exigência desse mine- ral para frangos de corte, pois, quando em excesso nas dietas, tende a acumular-se no fígado (Southern \& Baker, 1993; Black et al., 1984). Leeson \& Summers (2001) também relataram que a concentração de manganês no fígado responde à concentração do manganês dietético, como citado por Andriguetto (1981). Esse fato sugere que aves alimentadas nas fases anteriores (inicial e crescimento) com dietas contendo níveis consideráveis de manganês (70 ppm suplementar) possivelmente acumulam reservas desse mineral nos órgãos e tecidos.

Considerando-se a não-influência dos níveis de manganês sobre as variáveis de maior interesse econômico (ganho de peso, consumo de ração e conversão alimentar) e sobre a deposição nos ossos e que o fígado acumula o excesso de manganês fornecido nas dietas, sugere-se que os níveis de 30 a 40 ppm, normalmente presentes em dietas práticas à base de milho e farelo de soja, são suficientes para o desenvolvimento animal e que é desnecessária sua suplementação para frangos de corte, machos e fêmeas, de 43 a 54 dias de idade. 
Tabela 6 - Efeito dos diferentes níveis de manganês (Mn) na ração sobre a resistência do osso à quebra (ROQ), o comprimento da tíbia (CT) e a concentração de $\mathrm{Mn}$ no osso (MnO) e no fígado (MnF) de frangos de corte machos (M) e fêmeas (F) de 43 a 54 dias de idade

Table 6 - Effects of different dietary levels of manganese (Mn) on bone fracture resistance (ROQ), tibia length (CT), and Mn concentration in the bone (MnO) and in the liver (MnF) of male (M) and female (F) broilers from 43 to 54 days old

\begin{tabular}{|c|c|c|c|c|c|}
\hline $\begin{array}{l}\text { Nível de } \mathrm{Mn}(\mathrm{ppm}) \\
\text { Level of } M n\end{array}$ & $\begin{array}{l}\text { Sexo } \\
\text { Sex }\end{array}$ & ROQ(Kgf/mm) & $\mathrm{CT}(\mathrm{mm})$ & $\mathrm{MnO}(\mathrm{ppm})$ & $\operatorname{MnF}(p p m)$ \\
\hline 6,5 & M & 23,65 & 124,74 & 2,68 & 3,92 \\
\hline 66,5 & M & 19,73 & 126,57 & 2,85 & 4,75 \\
\hline 96,5 & M & 23,55 & 122,73 & 2,94 & 5,26 \\
\hline 126,5 & M & 22,20 & 126,02 & 2,94 & 5,25 \\
\hline \multicolumn{6}{|l|}{ Mean } \\
\hline 6,5 & $\mathrm{~F}$ & 20,66 & 118,59 & 2,93 & 3,80 \\
\hline 36,5 & $\mathrm{~F}$ & 22,69 & 118,77 & 3,16 & 4,68 \\
\hline 66,5 & $\mathrm{~F}$ & 20,08 & 119,68 & 3,14 & 5,37 \\
\hline 96,5 & $\mathrm{~F}$ & 20,53 & 119,05 & 3,26 & 5,42 \\
\hline Nível de Mn & & ns & ns & ns & $* * 1$ \\
\hline \multicolumn{6}{|l|}{ Level of Mn } \\
\hline Sexo & & ns & $* *$ & $* *$ & $* *$ \\
\hline \multicolumn{6}{|l|}{ Sex } \\
\hline Sexo x Níveis & & ns & ns & ns & ns \\
\hline \multicolumn{6}{|l|}{ Sex $x$ Levels } \\
\hline CV $(\%)$ & & 17,91 & 2,57 & 8,47 & 7,49 \\
\hline
\end{tabular}

Médias seguidas pela mesma letra na coluna não diferem a $5 \%$ pelo teste $\mathrm{F}$.

Averages followed by the same letter in the column do not differ at $5 \%$ by $F$ test.

$\mathrm{CV}$ - Coeficiente de variação (Coefficient of variation).

** $(\mathrm{P}<0,01) ; \mathrm{ns}(\mathrm{P}>0,05)$, pelo teste $\mathrm{F}$ (by $\mathrm{F}$ test).

${ }^{1}$ Efeito linear (Linear effect).

\section{Conclusões}

A exigência em manganês para frangos de corte, machos e fêmeas, é de 90 ppm na fase de crescimento. Os níveis de 30 a 40 ppm de manganês são suficientes para o desenvolvimento das aves na fase de terminação, não havendo necessidade de sua suplementação em dietas práticas à base de milho e farelo de soja.

\section{Literatura Citada}

ANDRIGUETTO, J.M. Nutrição animal. 4.ed. São Paulo: Nobel, 1981. v.1, p.396.

BLACK, J.R.; AMMERMAN, C.B.; HENRY, P.R. et al. Effect of dietary manganese and age on tissue trace mineral composition of broiler type chicks as a biossay of manganese sources. Poutry Science, v.64, p.688-693, 1984.

FIALHO, B.F.; LOPEZ, J.; BELLAVER, C. Influência de níveis de farelo de arroz integral e manganês no desempenho e nas características de ossos de frango de corte. Revista da Sociedade Brasileira de Zootecnia, v.22, n.5, p.830-838, 1993.
HENRY, P.R.; AMMERMAN, C.B.; MILES, R.D. Biovailability of manganese monoxide and manganese dioxide for broiler chicks. Nutrition Reports International, v.36, n.2, p.425433, 1986.

KEAKY, R.D.; SULLIVAN, T.W. Studies on manganese requeriment and interations in the diet of young turkeys. Poutry Science, v.45, n.6, p.1352-1358, 1966.

LEESON, S.; SUMMERS J.D. Nutrition of the chicken. 4.ed. Ontario: University Books, 2001. p.591.

MORRIS, T.R. The interpretation of response data from animal feeding trials. Recent Advances Animal Nutrition, v.6, p.1-11, 1983.

NATIONAL RESEARCH COUNCIL - NRC. Nutrient requirements of poutry. Nutrient requirements of poultry. Washington, D.C.: National Academic Press, 1994. p.44-45.

NOBRE, P.T.C. Exigência e biodisponibilidade de fontes inorgânicas de manganês para frangos de corte. Lavras: Escola Superior de Agricultura de Lavras, 1993. 59p. Dissertação (Mestrado em Zootecnia) - Escola Superior de Agricultura de Lavras, 1993.

ROSTAGNO, H.S.; ALBINO, L.F.T.; DONZELE, J.L. et al. Composição de alimentos e exigências nutricionais de aves e suínos (Tabelas Brasileiras). Viçosa, MG: Universidade Federal de Viçosa, 2000. 140p. 
UNIVERSIDADE FEDERAL DE VIÇOSA - UFV. SAEG Sistema para análise estatística e genética, versão 8.0. Viçosa, MG: Fundação Arthur Bernardes, 1999.

SCOTT, M.L. Poutry schort papers. Feedstuffs, v.53, n.29, p.16, 1981.

SILVA, D.J. Análise de alimentos (métodos químicos e biológicos). 2.ed. Viçosa, MG: Universidade Federal de Viçosa, 1998. 165p.
SOUTHERN, L.L.; BAKER D.H. Excess manganese ingestion in the chick. Poultry Science, v.62, p.642-646, 1983.

Recebido em: 11/05/04

Aceito em: 30/06/05 